\title{
Comparative estimation of metrological characteristics of different PCR types for quantitative material assessment in complex matrices on the example of soybeans' GM line
}

\author{
O.V. Prasolova*, I.V. Soltynskaya, A.V. Sukhoedova, M.A. Gergel, and L.K. Kish \\ The Russian State Center for Animal Feed and Drug Standardization and Quality (FGBU «VGNKI»), \\ Moscow, Russia
}

\begin{abstract}
A method of quantitative determination of genetically modified line (GM line) of soybean Mon 89788 based on digital PCR has been developed. Comparative analysis of metrological characteristics of this technique with identical based on PCR-RT was carried out. Both the detection limit and the quantitative detection limit of the methodology were defined. Correlation coefficient $(\mathrm{R} 2=0.9987)$ was close to the maximum value, indicating a good correlation of the analytical signal linear dependence of the GMO content in the panel samples. The digital PCR methodology allows to determine the GMO content in the range from $0.5 \%$ to $100 \%$. Compared to real time PCR results, digital PCR results show GMO content closer to the reference value; however, this technique does not allow to determine GMO content below $0.5 \%$.
\end{abstract}

\section{Introduction}

Due to its sensitivity and reliability, the real-time polymerase chain reaction (PCR-RT) is optimal for detection and quantification of the target material in matrices for more than two decades, especially in GMO research. However, given PCR-RT's dependence on inhibitors and standard curves to quantify the target matrix, scientists and practitioners are bound to look for alternatives to its determination [2,4,8]. Digital PCR (dPCR) is less sensitive to inhibitors present in complex samples and is independent of the reference material for standard curves [4].

For dPCR, the reaction mixture is divided into many separate reactions called partitions, each containing none, one or more target copies. Partitions are read as negative or positive at the endpoint, and the DNA concentration is calculated using Poisson distribution. The separation of reaction volumes into partitions is achieved using either holes on chip in dPCR based on microfluid/chip (dPCR) or droplets in dPCR based on emulsion/droplets (dPCR). Such approach allows to perform quantitative assessment

\footnotetext{
* Corresponding author: o.prasolova@vgnki.ru
} 
without compulsory requirement for standard curves. The purpose of this study was a comparison of standard metrological characteristics [3] of two types of polymerase chain reaction to overcome the problem of soybeans' GM lines quantification in complex samples considering inhibition $[5,6]$.

\section{Materials and methods}

Standard soybeans line GM samples MON89788 of different composition (from 100 to $0 \%$ GMO) were prepared by mixing samples of certified GM line sample (AOCS 0906-B) and unmodified soybean (AOCS 0906-A). For the study, $10 \mathrm{mg}$ of obtained homogeneous standard samples were used. DNA was extracted from panel samples containing $100 \%$, $75 \%, 50 \%, 25 \%, 10 \%, 5 \%, 2.5 \%, 1 \%, 0.5 \%, 0.1 \%, 0.1 \%, 0 \%$ of soybean MON89788 [1.7]. For the preparation of twenty-fold PCR-mix-1"20xlec-R6g", the following reagents were mixed in a $1.5 \mathrm{~cm}^{3}$ vial: primer 1 (Lec-F) $18 \mu \mathrm{mol} / \mathrm{dm}^{3}-9 \mathrm{~mm}^{3}$, primer 2 (Lec-R) 18 $\mu \mathrm{mol} / \mathrm{dm}^{3}-9 \mathrm{~mm}^{3}$, probe (Lec-Z) $15 \mu \mathrm{mol} / \mathrm{dm}^{3}-7.5 \mathrm{~mm}^{3}$, deionized water -24.5 $\mathrm{mm}^{3}$. For the preparation of twenty-fold PCR-mix-1 "20xMon89788-Fam", the following reagents were mixed in a $1.5 \mathrm{~cm}^{3}$ vial: Lec-F $14 \mu \mathrm{mol} / \mathrm{dm}^{3}-7 \mathrm{~mm}^{3}$, Lec-R $14 \mu \mathrm{mol} / \mathrm{dm}^{3}$ $-7 \mathrm{~mm}^{3}$, Lec-Z $5 \mu \mathrm{mol} / \mathrm{dm}^{3}-2.5 \mathrm{~mm}^{3}$, deionized water $-33.5 \mathrm{~mm}^{3}$.

The optimal DNA amount per digital PCR reaction is $2500-3000$ copies per reaction, which is $\sim 45-55 \mathrm{ng}$ per reaction for soybeans. The DNA concentration of the samples analyzed was measured using a fluorimeter and diluted up to $20 \mathrm{ng} / \mathrm{mm}^{3}$.

To carry out the reaction, the following reagents were mixed in a separate test $1.5 \mathrm{~cm}^{3}$ vial per reaction: $2 x$ PCR MasterMix from QuantStudio ${ }^{\mathrm{TM}}$ 3D Digital PCR Master Mix v2 $-8 \mathrm{~mm}^{3}, 20 \mathrm{x}$ MON89788-FAM mixture $-0.8 \mathrm{~mm}^{3}$, 20x Lec-R6G mixture $-0,8 \mathrm{~mm}^{3}$, DNA $\left(17-20 \mathrm{ng} / \mathrm{mm}^{3}\right)-2.7 \mathrm{~mm}^{3}$, deionized water $-3.7 \mathrm{~mm}^{3}$.

Chips preparation for amplification was carried out using the QuantStudio ${ }^{\mathrm{TM}}$ Digital PCR loader immediately after the PCR mixture preparation according to the manufacturer's instructions. QuantStudio ${ }^{\text {TM }}$ Digital Digital PCR Chip Kit v2 consumables set was used. Before loading into the amplifier, prepared chips with loaded samples can be stored in a clean dry dark place for no more than an hour.

The amplifier with the Dual Flat SampleBlock heatblock of the digital PCR system Quant Studio 3D was used to perform the amplification. Chips with prepared analyzed samples were installed in the device and the process of thermal cycling is started: stage 1 temperature retention $96^{\circ} \mathrm{C}-10 \mathrm{~min}$, Stage $2-60^{\circ} \mathrm{C}-2 \mathrm{~min}, 98^{\circ} \mathrm{C}-30 \mathrm{~s}$, number of cycles -39 , stage $3-$ temperature retention $60^{\circ} \mathrm{C}-2 \mathrm{~min}$, storage $-10^{\circ} \mathrm{C}$. After the end of amplification, the chips were dried at room temperature 10-15 minutes, excess liquid was removed. After PCR, chips with analyzed samples were one by one loaded into a reader that provides analysis of microcells' fluorescent signal, determining which cells contain the target and which do not. Preliminary results analysis was carried out automatically by the digital PCR reader software Quant Studio 3D. The results were stored on a USB drive in the form of eds-files and then uploaded to cloud storage at www.thermofisher.com for further analysis and storage.

Calculation of genomic copy content per $\mathrm{mm}^{3}$ of the DNA solution was carried out using AnalysSuite ${ }^{\mathrm{TM}}$ software. The values of confidence interval limits "CI" and precision values of "Precision FAM" and "Precision VIC" determination are calculated automatically considering the random distribution error of molecules on a chip in independent Poisson processes. "Precision" means the ability to reliably distinguish measurements; this value is calculated automatically by the program using formula (1) as the ratio of the maximum deviation of the confidence limit or the interval to the mean value $\lambda$. 


$$
\text { Precision }=\frac{\max \left(\operatorname{abs}\left(\lambda_{\text {UpperCBound,LowerCBound }}-\lambda\right)\right)}{\lambda}
$$

where $\lambda$ is the average value of the set sample concentration in genomic equivalents, copies $/ \mathrm{mm}^{3}$

The concept of maximum deviation is used because the confidence interval for the Poisson distribution is asymmetric.

\section{Results and Discussion}

\subsection{Quantitative determination of soybean GM line content MON89788 by digital PCR}

The results in eds-file format uploaded to www.thermofisher.com are automatically analyzed by QuantStudio ${ }^{\mathrm{TM}}$ 3D software AnalysSuite ${ }^{\mathrm{TM}}$ Software to evaluate quality of chips and amplification.

An example of displaying chips with satisfactory quality in QuantStudio ${ }^{\text {TM }}$ 3D AnalysSuite ${ }^{\mathrm{TM}}$ Software, Review Quality tab, is shown in Figure 2.
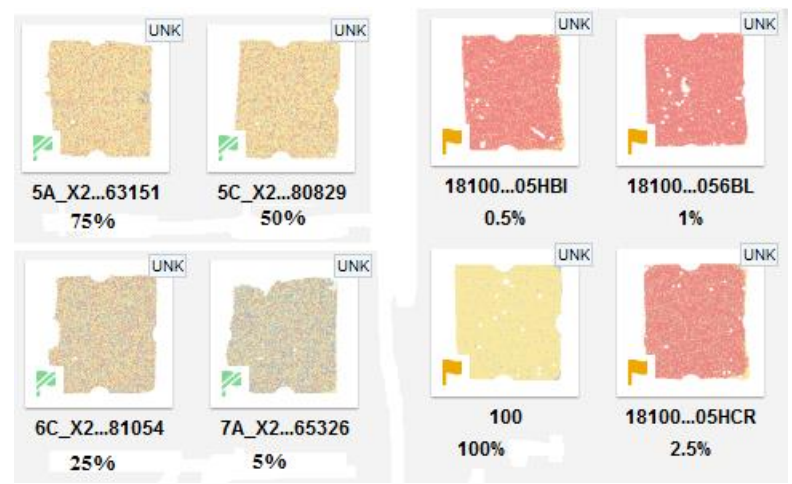

Fig. 1. Example display in QuantStudio ${ }^{\mathrm{TM}} 3 \mathrm{D}$ AnalysSuite ${ }^{\mathrm{TM}}$ Software of chips with high or satisfactory reading quality, green or yellow check box respectively

In the Review Calls tab of QuantStudio ${ }^{\text {TM }}$ 3D AnalysSuite ${ }^{\text {TM }}$ Software, we observed the distribution of chip microcells by fluorescence intensity on both channels (Figure 2). Genomic copies of MON89788 soybean are considered on the FAM channel, copies of the soybean lectin gene are taken into account on the VIC channel. 

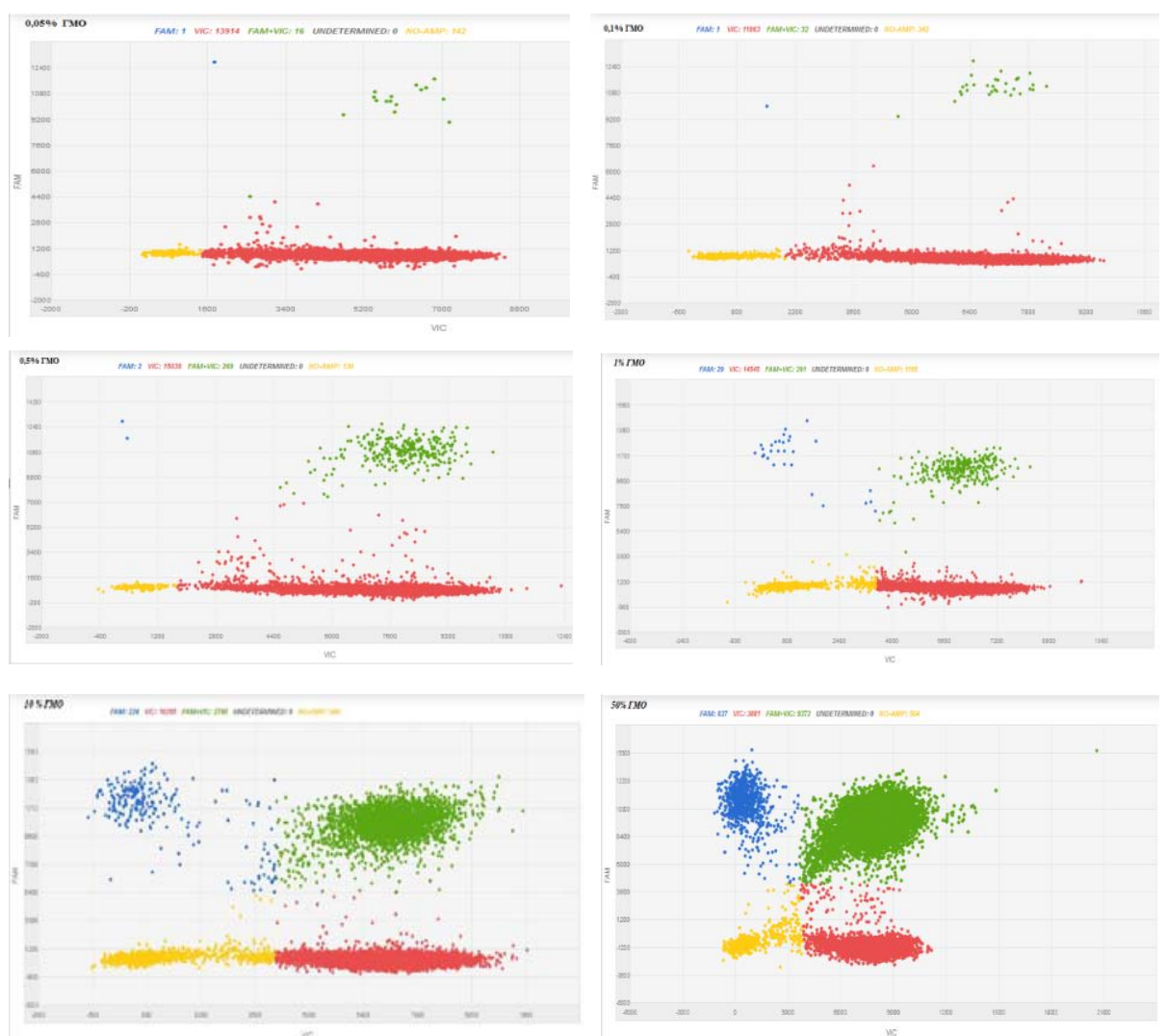

Fig. 2. Examples of reading chips with different GMO content - $0.05 \%, 0.1 \% 1 \%, 10 \%, 50 \%$

The distribution of chip microcells by fluorescence intensity is reflected on the FAM channel - vertically, on the VIC channel - horizontally. Yellow region - microcells without fluorescence accumulation on both channels (empty), red region - microcells with fluorescence accumulation only on the VIC channel (lectin gene amplification), blue region - microcells with fluorescence accumulation only on the FAM channel (MON89788 amplification), green area - microcells with fluorescence accumulation on both FAM and VIC channels (MON89788 and lectin gene amplification)

The detection limit of the digital PCR method was evaluated - the minimum amount of GMO in the studied sample, which is reliably detected. It is necessary that a statistically significant number of genomic GMO copies is identified (hit and amplification of target DNA in at least 100 chip microcells).

As can be seen from the results of experiments (Figure 3), the sample of $0.5 \%$ GMO contains more than 100 microcells with MON89788 DNA (2 FAM+269 FAM+VIC cells). In the samples, $0.1 \%$ and $0.05 \%$, GMO DNA only hit 33 and 17 cells, respectively.

Thus, the detection limit of this methodology is $0.5 \%$ GMO.

Indicator of precision characterizes the confidence interval. For example, if the sample concentration is defined as 1 copy $/ \mathrm{mm}^{3}$ with $0.9-1.1$ confidence interval $(95 \%)$, the calculated deviation from the random Poisson distribution of molecules over the chip will be $10 \%$ (with the probability of $5 \%$ of the event that the true concentration does not fall within the range of $0.9-1.1$ ). 
Table 1. Measurements results of GM content of MON89788 line by digital PCR

\begin{tabular}{|c|c|c|c|c|c|c|c|c|}
\hline \multirow[b]{2}{*}{$\begin{array}{c}\text { No } \\
\text {. }\end{array}$} & \multirow[b]{2}{*}{$\begin{array}{c}\text { GM } \\
\text { O } \\
\text { conte } \\
\text { nt, } \%\end{array}$} & \multicolumn{7}{|c|}{ Obtained result } \\
\hline & & $\begin{array}{l}\text { genomic } \\
\text { equivalent } \\
\text { on the } \\
\text { VIC } \\
\text { channel, } \\
\text { copies } \\
/ \mathrm{mm}^{3}\end{array}$ & $\begin{array}{c}\text { CI } \\
\text { VIC } \\
\text { channel, } \\
\text { copies/m } \\
\mathrm{m}^{3}\end{array}$ & $\begin{array}{c}\text { Precisi } \\
\text { on VIC } \\
\text { channe } \\
1\end{array}$ & $\begin{array}{c}\text { Genomic } \\
\text { equivalen } \\
\mathrm{t} \text { on FAM } \\
\text { channel, } \\
\text { copies } / \mathrm{m} \\
\mathrm{m}^{3}\end{array}$ & $\begin{array}{c}\text { CI } \\
\text { FAM } \\
\text { channel, } \\
\text { copies/m } \\
\mathrm{m}^{3}\end{array}$ & $\begin{array}{l}\text { Precision } \\
\text { FAM }\end{array}$ & $\begin{array}{c}\text { Identified } \\
\text { GMO } \\
\text { content, \% } \\
\frac{\text { Copies } / \mu l(F A M)}{\text { Copies } / \mu /(M C)} * 100 \%\end{array}$ \\
\hline 1 & 2 & 3 & 4 & 5 & 6 & 7 & 8 & 9 \\
\hline 1 & $\mathbf{0}$ & 3630.7 & $\begin{array}{l}3548.8 \\
3714.5 \\
\end{array}$ & $2.31 \%$ & 0.09 & $\begin{array}{c}0.0128 \\
0.645 \\
\end{array}$ & $609.93 \%$ & 0.002 \\
\hline 2 & 0.05 & 6172 & $\begin{array}{l}5953 \\
6399 \\
\end{array}$ & $3.68 \%$ & 1.6 & $\begin{array}{l}0.99 \\
2.58 \\
\end{array}$ & $60.86 \%$ & 0.03 \\
\hline 3 & 0.1 & 4782.3 & $\begin{array}{l}4643.3 \\
4925.4\end{array}$ & $2.99 \%$ & 3.468 & $\begin{array}{c}2.45 \\
4.9\end{array}$ & $41.41 \%$ & 0.07 \\
\hline 4 & 0.5 & 5625.7 & $\begin{array}{l}5458.7 \\
5797.9\end{array}$ & $3.06 \%$ & 21.07 & $\begin{array}{l}18.71 \\
23.73\end{array}$ & $12.62 \%$ & 0.37 \\
\hline 5 & 1 & 3511.8 & $\begin{array}{l}3436.9 \\
3588.4\end{array}$ & $2.18 \%$ & 26.68 & $\begin{array}{l}23.91 \\
29.77\end{array}$ & $11.58 \%$ & 0.76 \\
\hline 6 & 2.5 & 2914.2 & $\begin{array}{c}2858 \\
2971.6\end{array}$ & $1.97 \%$ & 107.42 & $\begin{array}{l}101.79 \\
113.36\end{array}$ & $5.53 \%$ & 3.15 \\
\hline 7 & 5 & 1064.5 & $\begin{array}{l}1042.6 \\
1086.8\end{array}$ & $2.09 \%$ & 83.43 & $\begin{array}{l}78.54 \\
88.63\end{array}$ & $6.23 \%$ & 7.83 \\
\hline 8 & 10 & 3315.2 & $\begin{array}{l}3242.6 \\
3389.4\end{array}$ & $2.24 \%$ & 314.53 & $\begin{array}{l}303.47 \\
325.99\end{array}$ & $3.65 \%$ & 9.49 \\
\hline 9 & 25 & 3221.9 & $\begin{array}{l}3154.8 \\
3290.4\end{array}$ & $2.13 \%$ & 720.54 & $\begin{array}{c}703.1 \\
738.42\end{array}$ & $2.48 \%$ & 22.36 \\
\hline 10 & 50 & 3332.3 & $\begin{array}{l}3259.6 \\
3406.6\end{array}$ & $2.23 \%$ & 1626.8 & $\begin{array}{c}1593.4 \\
1661\end{array}$ & $2.1 \%$ & 48.81 \\
\hline 11 & 75 & 3018.2 & $\begin{array}{l}2956.9 \\
3080.8\end{array}$ & $2.07 \%$ & 2056.2 & $\begin{array}{l}2016.2 \\
2096.9\end{array}$ & $1.98 \%$ & 68.1 \\
\hline 12 & 100 & 1398.8 & $\begin{array}{c}1371 \\
1427.2\end{array}$ & $2.03 \%$ & 1353.5 & $\begin{array}{l}1326.4 \\
1381.1\end{array}$ & $2.04 \%$ & 96.8 \\
\hline
\end{tabular}

Quantification limit was evaluated by Precision FAM and Precision VIC indicators (Table 1), which characterizes the relative deviation for the data obtained. These values should not exceed $25 \%$ on each channel.

For samples with GMO content of $0.5 \%$ or more, the accuracy of both detection channels (FAM, VIC) satisfies the criteria - Precision FAM and Precision VIC indicators did not exceed $25 \%$ on both channels. However, this methodology does not allow to determine GMO content below 0.5\%, the indicator "Precision FAM" exceeds 25\% (table 1). Quantification methodology limit $0.5 \%$.

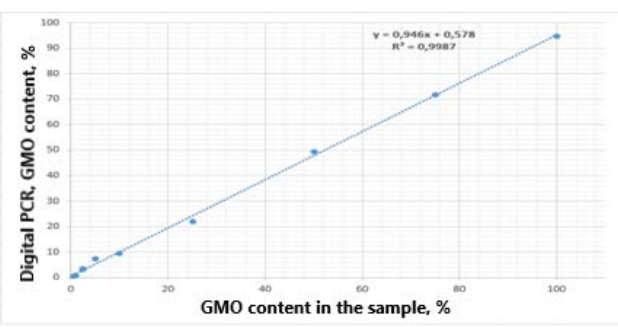

Fig. 3. Results dependance linearity estimation by digital PCR panel samples method 
Linearity in the analytical area of digital PCR methodology was evaluated when constructing the dependence of GMO content values obtained during the study of a panel with known (reference) values of GMO content (Figure 3). Correlation coefficient $\left(\mathrm{R}^{2}=0.9987\right)$ was close to the maximum value, indicating a good correlation of the analytical signal linear dependence of the GMO content in the panel samples. Table 1 shows that the deviation of GMO content determination results from reference values is negligible. Thus, the digital PCR methodology allows to determine the GMO content in the range from $0.5 \%$ to $100 \%$.

Based on the study of the digital PCR method possibilities, the criteria for assessing the suitability of methods for determining GMO based on it were selected:

- the detection limit not less than $0.5 \%$, the criterion is defined as the presence of at least 100 microcells with the target DNA on the chip.

- quantitative determination limit of not less than $0.5 \%$ (threshold value of GMO content in products. The "Precision" indicator, which characterizes the relative standard deviation of the Poisson distribution, should not exceed 25\%).

- the dependence of the obtained results (GMO content) of reference samples on expected GMO content must satisfy the linear model in the range from 0.5 to $100 \%\left(\mathrm{R}^{2}\right.$ more than 0.98).

\subsection{Quantification of soybean GM line content MON89788 by real-time PCR}

To compare digital PCR and PCR with hybridization fluorescent detection in real time, a panel of samples prepared from certified standard samples of GMO flour (AOCS 0906-B) and unmodified soybean (AOCS 0906-A) were studied. [6].

Calibration lines were built using $0.1 \%, 1 \%$ and $5 \%$ of panel samples and over the entire range of concentrations used in the GMO panel — from 0.1 to $100 \%$ (Figure 4-5).
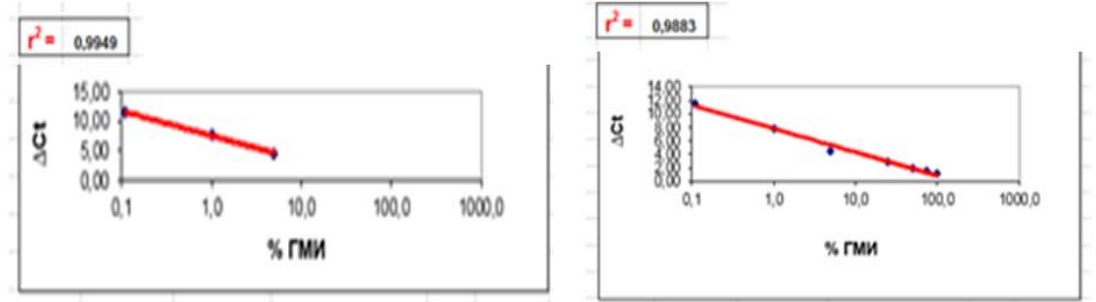

Fig. 4-5. Estimation of the quantitative content of the MON89788 soybean line in the sample panel using the calibration line in the range of $0.1-5 \%$ and in the range of $0.1-100 \%$

The results make it clear that the exact quantity determination is possible only within the $0.1-5 \%$ analytical range of the methodology. The high GMO content of the sample from $10 \%$, is determined with low reliability, for example, $100 \%$ sample is defined as "34.3\%" (Figure 5). In the construction of a calibration line over the entire concentrations range used in the GMO panel - from $0.1 \%$ to $100 \%$, the determination accuracy of high concentrations increases, but nevertheless the definition occurs with low accuracy. For example, $2.5 \%$ value is defined as " $4.6 \%$ ", the value of $5 \%$ is defined as " $9.0 \%$ ", the value of $100 \%$ as " $82.7 \%$ " (Fig. 5).

Compared to real-time PCR, digital PCR results show the value of GMO content closer to the reference (Table 2). However, digital PCR does not allow determining GMO content below $0.5 \%$. 
Table 2. Results obtained for GMO sample panel by digital PCR and real-time PCR

\begin{tabular}{|c|c|c|c|c|}
\hline \multirow{2}{*}{ Panel } & \multirow{2}{*}{$\begin{array}{c}\text { Expected } \\
\text { result }\end{array}$} & \multicolumn{3}{|c|}{ Obtained result } \\
\cline { 3 - 5 } & & Digital PCR & $\begin{array}{c}\text { PCR RT } \\
\mathbf{0 , 1 \% - 5 \%}\end{array}$ & $\begin{array}{c}\text { PCR-RT } \\
\mathbf{0 , 1} \mathbf{- 1} \mathbf{- 1 0 0} \%\end{array}$ \\
\hline non-GMO & $0 \%$ & 0.002 & 0.01 & 0.00 \\
\hline $0,1 \%$ GMO & $0.1 \%$ & 0.05 & 0.12 & 0.09 \\
\hline $0,5 \%$ GMO & $0.5 \%$ & 0.44 & 0.52 & 0.54 \\
\hline $1 \%$ ГMO & $1 \%$ & 0.76 & 0.85 & 0.98 \\
\hline $2,5 \%$ GMO & $2.5 \%$ & 3.15 & 3.13 & 4.67 \\
\hline $5 \%$ GMO & $5 \%$ & 7.37 & 5.42 & 9.04 \\
\hline $10 \%$ GMO & $10 \%$ & 9.49 & 6.11 & 10.44 \\
\hline $25 \%$ GMO & $25 \%$ & 21.97 & 13.15 & 26.16 \\
\hline $50 \%$ GMO & $50 \%$ & 49.39 & 21.02 & 45.91 \\
\hline $75 \%$ GMO & $75 \%$ & 71.68 & 27.69 & 63.87 \\
\hline $100 \%$ GMO & $100 \%$ & 95.8 & 34.34 & 82.7 \\
\hline
\end{tabular}

\section{Conclusions}

The advantage of the digital PCR method for determining the content of MON89788 soybean line is the lack of need to use standard samples in routine studies. MON89788 soybean line determination method by digital PCR is suitable for research of fodder, feed additives, food products and raw materials. The detection limit of the digital PCR methodology is $0.5 \%$ GM line MON89788 in the sample of unmodified soybeans. The analytical area of the methodology is $0.5 \%-100 \% \mathrm{GMO}$, which is much wider than the analytical area of the Mon 89788 soybean line quantification based on RT-PCR $(0.1 \%$ $5 \%$ ). Thus, the digital PCR method allows to determine the GMO content in the sample at high GMO content more accurately. Disadvantages of the digital PCR method include low sensitivity, detection limit and $0.5 \%$ quantification limit.

\section{References}

1. S. Broeders, N. Papazova, M. Van den Bulcke, N. Roosens, Development of a molecular platform for GMO detection in food and feed on the basis of 'combinatory qPCR' technology (2012)

2. A.B. Košir, T. Demšar, D. Štebih, Ž. Jana, M. Milavec, Food Chemistry, 73 (2019)

3. A.B. Košir, B. Spilsberg, A. Holst-Jensen, J. Žel, D. Dobnik, Scientific Reports, 7(1), 8601 (2017)

4. M. Mazzara, C. Savini, H. Delobel, H. Broll, A. Damant, C. Paoletti, G. Van den Eede, European Network of GMO Laboratories (ENGL), 1 (2008)

5. D. Morisset, D. Stebih, K. Cankar, J. Zel, K. Gruden, European Food Research and Technology (2008)

6. E. Navarro, G. Serrano-Heras, M. Castaño, J. Solera, Clinica Chimica Acta, 439, 231 (2015)

7. M. Querci, M. Van den Bulcke, J. Žel, G. Van den Eede, H. Broll, Analytical and Bioanalytical Chemistry, 396(6), 1991 (2010)

8. J. Wan, L. Song, Y. Wu, P. Brzoska, D. Keys, C. Chen, B. Valliyodan, G. Shannon, H.T. Nguyen, Advances in Bioscience and Biotechnology, 07(10), 403 (2016) 